\title{
Comparative study of abdominal, vaginal and laparoscopic assisted vaginal hysterectomies with special reference to immediate sequel, late sequel and complications
}

\author{
Pujitha Devi Suraneni $^{1 *}$, Sradhanjali Maharana ${ }^{2}$
}

Assistant Professor ${ }^{1}$, Associate Professor ${ }^{2}$, Department of Obstetrics and Gyanecology, Malla Reddy Institute of Medical Sciences, Hyderabad, Telangana, India

Received: 03 December 2015

Accepted: 07 January 2016

\section{*Correspondence:}

Dr. Pujitha Devi Suraneni,

E-mail: suranenipujitha@yahoo.co.in

Copyright: ( $)$ the author(s), publisher and licensee Medip Academy. This is an open-access article distributed under the terms of the Creative Commons Attribution Non-Commercial License, which permits unrestricted non-commercial use, distribution, and reproduction in any medium, provided the original work is properly cited.

\begin{abstract}
Background: Hysterectomy can be performed by abdominal, vaginal or laparoscopic assisted procedure. Each procedure has its own indications, contraindications, complications, advantages and disadvantages. The objective was to compare abdominal, vaginal and laparoscopic assisted vaginal hysterectomies, with special reference to immediate and late sequel and complications.

Methods: Hospital based cross sectional study was carried out for a period of two years among selected 60 women who underwent hysterectomy. Detailed history, complete clinical, obstetric examination, and all necessary investigations were carried out. Comparison in relation to complications, duration of surgery etc for the three types of hysterectomy was done.

Results: The vaginal hysterectomy was found to be more advantageous in cases with uterus less than 12 weeks size and without gross adnexal pathology and laparoscopic hysterectomy is advantageous for the cases with large fibroid, ovarian pathology, endometriosis, adenomyosis or adhesions.

Conclusions: Preference for laparoscopic assisted vaginal hysterectomy or vaginal hysterectomy depends on expertise of doctor and selections of patients.
\end{abstract}

Keywords: Vaginal hysterectomy, Complications, Sequel

\section{INTRODUCTION}

Hysterectomy is most common major operation after Caesarean Section. ${ }^{1}$ Abdominal hysterectomy accounted for $63 \%$ of all hysterectomies in the United States in 1997 whereas vaginal hysterectomy accounted for $9.9 \%$ of the total hysterectomies. ${ }^{2}$ In the United States one third of the women can be expected to have a hysterectomy by age $60 .^{3}$

The advantages of abdominal hysterectomy are that it provides surgeon good visibility and easy access to the pelvic organs, enables removal of a very large uterus and large areas of endometriosis, adenomyosis, and scar tissue, cervix can be removed or left in space, required less time under anesthesia and in surgery than laparoscopic hysterectomy. ${ }^{4}$ At the same time the disadvantages are painful abdominal incision, longer hospital stay and recovery time, a large scar, longer convalescence, costs more than vaginal hysterectomy. ${ }^{5}$

The advantages of vaginal hysterectomy are that it enables removal of normal to slightly larger than normal uterus and small uterine fibroids, less pain, does not cause scars, less manipulation of intestines, morbidity associated with abdominal incision is avoided, reduces the depth and height of anesthesia, need for nursing care is reduced etc. ${ }^{6}$ The disadvantages are don't allow free access to the pelvic organs. ${ }^{7}$ 
In view of advantages and disadvantages of abdominal and vaginal hysterectomy, recently used laparoscopic assisted vaginal hysterectomy (LAVH) is considered to be safer but it also carries some complications.

Hence present study was undertaken to compare these techniques with special reference to immediate and late sequel and complications following these operations.

\section{METHODS}

\section{Study type}

Hospital based cross sectional comparative study.

\section{Study place}

Department of Obstetrics and Gynecology, Chalmeda Anand Rao Institute of Medical Sciences, Karimnagar

\section{Study period}

Two years

\section{Ethical considerations}

Institutional Ethics committee permission was taken prior to the study. Informed consent was taken from each and every patient.

\section{Sample size}

60 cases of hysterectomy of which 20 were abdominal, 20 were simple vaginal and remaining 20 were LAVH.

\section{Inclusion criteria}

Patients with

1. Dysfunctional Uterine Bleeding,

2. Uterine fibroid cervical dysplasia,

3. Endometriosis and

4. Adenomyosis,

Complete history, detailed clinical, gynecological examination was carried out. All necessary investigations were performed.

Details about the operation like, duration of surgery, type of anesthesia, findings at operation, complications during operation and history any intra-operative blood transfusion are noted. Postoperatively the following points are noted:

1. Any complications

2. postoperative pain and requirement for analgesics

3. Ambulation

4. Bowel sounds

\section{Parenteral fluid requirements}

At the time of discharge advice about HRT is given if the ovaries are removed and all the patients were asked to come for follow up at OPD after 6 weeks.

\section{RESULTS}

Table 1: Comparison of duration of the surgery.

\begin{tabular}{|ll|}
\hline Type of hysterectomy & Duration of surgery \\
\hline Abdominal & $45-55$ mins \\
\hline Vaginal & $40-50$ mins \\
\hline LAVH & $60-120$ mins \\
\hline
\end{tabular}

Technical difficulties were encountered with 2 cases of LAVH. In these cases cautery did not work during the procedure and hence duration of surgery was very much prolonged.

Table 2: Comparison of intra operative complications in different types of hysterectomies.

\begin{tabular}{|lllll|}
\hline Complication & Abdominal & Vaginal & LA VH & $\%$ \\
\hline Hemorrhage & 2 & 3 & 0 & $8.3 \%$ \\
\hline Bladder injury & 0 & 0 & 0 & $0.0 \%$ \\
\hline $\begin{array}{l}\text { Anaesthesia } \\
\text { related }\end{array}$ & 0 & 0 & 1 & $1.0 \%$ \\
\hline Bowel injury & 0 & 0 & 0 & $0.0 \%$ \\
\hline
\end{tabular}

Hemorrhage was not observed in patients who underwent LAVH. 1 case of LAVH had late recovery from anesthesia. Intra operative blood transfusion was given to 2 cases of abdominal hysterectomy, 2 case of vaginal hysterectomy and nil for LAVH cases.

Table 3: Comparison of postoperative ambulation among different types of hysterectomies.

\begin{tabular}{|llll|}
\hline $\begin{array}{l}\text { Post } \\
\text { operative day }\end{array}$ & AH & VH & LA VH \\
\hline $1^{\text {st }}$ & $13(65 \%)$ & $18(90 \%)$ & $20(100 \%)$ \\
\hline $2^{\text {nd }}$ & $4(20 \%)$ & $2(10 \%)$ & 0 \\
\hline $3^{\text {rd }}$ & $3(15 \%)$ & 0 & 0 \\
\hline$X^{2}$ & & & \\
\hline
\end{tabular}

$\mathrm{X}^{2}=11.53, \mathrm{p}=0.02122, \mathrm{~S}$

Table 4: Comparison of post operative requirement of analgesics.

\begin{tabular}{|llll|}
\hline $\begin{array}{l}\text { Post } \\
\text { operative day }\end{array}$ & AH & VH & LA VH \\
\hline $1^{\text {st }}$ & $20(100 \%)$ & $20(100 \%)$ & $20(100 \%)$ \\
\hline $2^{\text {nd }}$ & $18(90 \%)$ & $10(50 \%)$ & $5(25 \%)$ \\
\hline $3^{\text {rd }}$ & $15(75 \%)$ & $3(15 \%)$ & 0 \\
\hline $\mathrm{X}^{2}=16.97 ; \mathrm{p}=0.001962, \mathrm{~S}$ & & \\
\hline
\end{tabular}

Of the patients who underwent abdominal hysterectomy only $65 \%$ of patients ambulated on $1^{\text {st }}$ postoperative day. 
$20 \%$ of them were ambulatory on $2^{\text {nd }}$ postoperative day. Remaining were ambulatory on $3^{\text {rd }}$ postoperative day. It was observed that $90 \%$ of vaginal hysterectomy patients were ambulatory on $1^{\text {st }}$ postoperative day itself. Only $10 \%$ were ambulatory on $2^{\text {nd }}$ postoperative day. Ambulation was observed earliest in patients who underwent LAVH. All of the patients in this group were ambulatory on $1^{\text {st }}$ postoperative day.

Postoperative pain and requirement for analgesics was greatest with patients who underwent abdominal hysterectomy and least with patients who underwent LAVH.

Table 5: Comparison of post operative return of bowel sounds.

\begin{tabular}{|c|c|c|c|}
\hline Post & $\mathbf{A H}$ & VH & LAVH \\
\hline \multicolumn{4}{|c|}{ operative day } \\
\hline $1^{\mathrm{st}}$ & 0 & $20(100 \%)$ & $20(100 \%)$ \\
\hline $2^{\text {nd }}$ & $18(90 \%)$ & 0 & $5(25 \%)$ \\
\hline $3^{\text {rd }}$ & $2(10 \%)$ & 0 & 0 \\
\hline
\end{tabular}

$\mathrm{X}^{2}=60 ; \mathrm{p}=0.0000001, \mathrm{NS}$

In majority of patients who underwent abdominal hysterectomy bowel sounds returned on $2^{\text {nd }}$ postoperative day. Bowel sounds returned on $1^{\text {st }}$ postoperative day in patients who underwent vaginal hysterectomy and LAVH. In only $30 \%$ of them bowel sounds returned back on $1^{\text {st }}$ postoperative day in the evening.

Table 6: Comparison of early post operative complications.

\begin{tabular}{|lllll|}
\hline $\begin{array}{l}\text { Type of } \\
\text { complication }\end{array}$ & $\begin{array}{l}\text { Abdo } \\
\text { minal }\end{array}$ & Vaginal & LA VH & $\%$ \\
\hline Hemorrhage & 0 & 0 & 0 & $0.0 \%$ \\
\hline Pyrexia & 5 & 3 & 0 & $0.13 .3 \%$ \\
\hline $\begin{array}{l}\text { Anaesthesia } \\
\text { complications }\end{array}$ & 1 & 2 & 0 & $5.0 \%$ \\
\hline Peritonitis & 0 & 0 & 0 & $0.0 \%$ \\
\hline $\begin{array}{l}\text { Wound sepsis } \\
\text { Partial }\end{array}$ & 3 & 0 & 0 & $5.0 \%$ \\
dehiscence & 1 & 0 & 0 & $1.6 \%$ \\
\hline $\begin{array}{l}\text { Total } \\
\text { dehiscence }\end{array}$ & 0 & 0 & 0 & $0.0 \%$ \\
\hline $\begin{array}{l}\text { Pulmonary } \\
\text { problems }\end{array}$ & 0 & 0 & 0 & $0.0 \%$ \\
\hline $\begin{array}{l}\text { Burst } \\
\text { abdomen }\end{array}$ & 0 & 0 & 0 & $0.0 \%$ \\
\hline $\begin{array}{l}\text { Urinary } \\
\text { problems }\end{array}$ & 6 & 4 & 1 & $16 \%$ \\
\hline \begin{tabular}{l} 
GI T upset \\
\hline
\end{tabular} & 4 & 2 & 0 & $10.0 \%$ \\
\hline
\end{tabular}

Pyrexia was most commonly seen in patients who underwent abdominal hysterectomy. $40 \%$ of these patients underwent abdominal hysterectomy and $20 \%$ underwent vaginal hysterectomy. None of the patients of LAVH had pyrexia. Post spinal headache was observed in 1 case of abdominal hysterectomy and 2 cases of vaginal hysterectomy. Diarrhea and G I T upset was observed in 4 cases of abdominal against 2 cases of vaginal and nil in LAVH cases. In the abdominal cases majority had urinary retention and needed catheterization. Of vaginal hysterectomy cases 9 cases had urinary tract infection. 3 cases of abdominal hysterectomy had wound sepsis. None of the vaginal hysterectomy or LAVH cases had any wound infection in this study. Partial dehiscence not involving the rectus sheath was found in 1 case of abdominal hysterectomy.

Table 7: Comparison of Late post operative complications.

\begin{tabular}{|lll|ll|}
\hline $\begin{array}{l}\text { Type of } \\
\text { complications }\end{array}$ & $\begin{array}{l}\text { Abdo } \\
\text { minal }\end{array}$ & $\begin{array}{l}\text { Vag- } \\
\text { inal }\end{array}$ & LA VH & $\%$ \\
\hline Vault granulation & 1 & 1 & 0 & $3.3 \%$ \\
\hline Hemorrhage & 0 & 0 & 0 & $0.0 \%$ \\
\hline Pyrexia & 0 & 0 & 0 & $0.0 \%$ \\
\hline Incisional hernia & 0 & 0 & 0 & $0.0 \%$ \\
\hline $\begin{array}{l}\text { Prolapse of } \\
\text { fimbrial end }\end{array}$ & 0 & 0 & 0 & $0.0 \%$ \\
\hline Omental prolapse & 0 & 0 & 0 & $0.0 \%$ \\
\hline Port site hernia & 0 & 0 & 0 & $0.0 \%$ \\
\hline Urinary problems & 2 & 1 & 0 & $5.0 \%$ \\
\hline Psychological & 0 & 0 & 0 & $0.0 \%$ \\
\hline
\end{tabular}

Vault granulation was seen in 1 case of abdominal hysterectomy and one case of vaginal hysterectomy and nil in LAVH cases. 2 cases of abdominal hysterectomy and 1 case of vaginal hysterectomy had complications of burning micturition.

\section{DISCUSSION}

In this study emphasis is laid on the comparative aspects of different types of hysterectomies in 60 randomly selected cases. 20 cases were taken for abdominal hysterectomy, 20 cases were vaginal hysterectomy and 20 cases were LAVH. In order to get proper results, similar cases were selected for comparison.

In our series, we had carefully evaluated clinically and excluded descended uterus and adnexal pathology .We have included only abnormal uterine bleeding, fibroids, endometriosis, adenomyosis, and cervical dysplasias in our study.

Our primary aim was to evaluate and compare preoperative, Intraoperative and postoperative complications in these three types of hysterectomies.

Studies by Summit, Ottosen, Hwang, Garry et al, Rosita A et al. ${ }^{8-11}$

2007, found that in their studies shows that there is least blood loss in the laparoscopic assisted vaginal hysterectomy. ${ }^{12}$ Though there is no much difference 
between these three groups in amount loss, hemostasis is more easily obtained at laparoscopic assisted vaginal hysterectomy because of magnification, close inspection, routine use of suction irrigation and bipolar cautery. In the present study 5 cases had excessive blood of which 2 cases underwent abdominal hysterectomy and 3 cases underwent vaginal hysterectomy. Among these 5 cases, 2 cases had borderline anaemia preoperatively.

Ottosen, Ribiero, and Garry et al in their studies showed that the bladder injuries are more in laparoscopic assisted vaginal hysterectomy followed by vaginal hysterectomy. Meikle SF, Nugent EW, Orleans $M$ in found greater incidence of bladder injury $1.8 \%$ in LAVH cases compared to abdominal hysterectomy where it was only $0.4 \% .^{9,11,13,14}$ In Present study none of the patients had this complication.

Studies done by Ottosen, Ribiero, and Garry et al in their studies showed that there was no significant difference between abdominal and laparoscopic assisted vaginal hysterectomy in ureter injuries during surgery. ${ }^{9,11,13}$ Present study shows no ureter injury.

Studies by Ottosen, Garry et al and G. McCracken et al shows that post operative ambulation is early in laparoscopic assisted vaginal hysterectomy followed by vaginal hysterectomy. ${ }^{9,11,15}$ Ambulation is delayed in abdominal hysterectomy. Present study shows the similar findings.

Studies by Ottosen, Garry et al and G. McCracken et al shows that the post operative requirement of analgesics is more in the abdominal hysterectomy followed by vaginal hysterectomy. ${ }^{9,11,15}$ Requirement of analgesics is least in laparoscopic assisted vaginal hysterectomy. Present study shows the similar findings.

Studies by Ottosen, Garry et al and G. McCracken et al shows that the post operative return of bowel sounds is early in the laparoscopic assisted vaginal hysterectomy followed by vaginal hysterectomy and delayed in abdominal hysterectomy. ${ }^{9,11,15}$ Present shows similar findings.

Studies by Ottosen, Garry et al and G. McCracken et al shows that the post operative requirement of parenteral fluids is more in the abdominal hysterectomy followed by vaginal hysterectomy and least in laparoscopic assisted vaginal hysterectomy. ${ }^{9,11,15}$

Post spinal headache was observed in 1 case of abdominal hysterectomy and 2 cases of vaginal hysterectomy.

Ferrari, Schutz, Garry, Muzii and Kulviers studies showed that laparoscopic assisted vaginal hysterectomy is generally associated with less post operative pain and less need for analgesics when compared to abdominal hysterectomy. ${ }^{11,16-19}$
Present study shows that one patient who underwent abdominal hysterectomy had partial gapping and required resuturing. Amirika and Evans in found partial gapping of wound as high as $10.4 \%$ and vault infection was $4.6 \%$. $^{20}$

Present study shows urinary tract infection in $10 \%$ of abdominal hysterectomy, $15 \%$ of vaginal hysterectomy and $1.6 \%$ of laparoscopic assisted vaginal hysterectomy. In all the cases urine was sent for culture and sensitivity and treated accordingly. Meikle SF, Ottosen, Hwang $\mathrm{G}^{14,9,10}$ McCracken et al observed that urinary tract infections are more common in vaginal hysterectomy followed by abdominal hysterectomy and then in laparoscopic assisted vaginal hysterectomy. ${ }^{15}$

In the present study vault granulation was seen in only 2 cases $(3.3 \%)$ which were treated with chemical cautery. Ottosen found 2 cases with vault granulations, one in vaginal hysterectomy and one in LAVH. $^{9}$ These studies show that risk of vault granulation is similar in abdominal, vaginal and laparoscopic assisted vaginal hysterectomies.

Ottosen observed secondary hemorrhage in 2 cases, one in abdominal hysterectomy and one in LAVH. ${ }^{9}$ Garry et al observed secondary hemorrhage in 2 cases, one in abdominal hysterectomy and one in vaginal hysterectomy. ${ }^{11}$ G. McCracken et al observed secondary hemorrhage in 1 case that underwent abdominal hysterectomy. ${ }^{15}$ These studies show that secondary hemorrhage occurs more in abdominal hysterectomy and least in LAVH. Present study shows no such complication.

Ottosen, Hwang, and Garry et al observed that pyrexia as a late complication is more in cases who underwent abdominal hysterectomy than in vaginal hysterectomy and LAVH. ${ }^{9-11}$ Present shows no such complication.

Summit et al, Ribiero, Garry et al found bladder is more common with LAVH than vaginal hysterectomy. No bladder injuries are found in our study. $8,11,13$

Ribiero, Garry et al observed that ureteric injuries are more common with LAVH than abdominal and vaginal hysterectomy. No ureteric injuries are found in our study. ${ }^{11,13}$

Ottosen observed bowel injury in 1 case that underwent LAVH and Garry et al ${ }^{11}$ observed bowel injury in 2 cases, one is with abdominal hysterectomy and one is with LAVH. ${ }^{9}$ These studies show that bowel injuries are common in LAVH followed by abdominal hysterectomy and less in vaginal hysterectomy. Present study had no bowel injuries.

Ottosen, Ribiero, Garry et al observed fistula in vaginal and laparoscopic assisted vaginal hysterectomies. $9,11,13$ These studies show those fistulas are common in vaginal 
hysterectomy and LAVH than in abdominal hysterectomy. Present study shows no fistula formation.

Ottosen, Hwang, Ribiero, Garry et al and G. McCracken et al observed $20 \%$ of their patients with depression, sexual dysfunction, backache and dyspaurenia. ${ }^{9-11,15}$ Such observation has not been done in this aspect in this series as most of the patients do not come out with proper marital history.

\section{CONCLUSIONS}

In conclusion the vaginal hysterectomy is found to be more advantageous in cases with uterus less than 12 weeks size and without gross adnexal pathology and laparoscopic hysterectomy is advantageous for the cases with large fibroid, ovarian pathology, endometriosis, adenomyosis or adhesions. Hence preference for laparoscopic assisted vaginal hysterectomy or vaginal hysterectomy depends on expertise of doctor and selections of patients.

\section{Funding: No funding sources}

Conflict of interest: None declared

Ethical approval: The study was approved by the Institutional Ethics Committee

\section{REFERENCES}

1. Rock JA, Jones HW, editors. Te Linde's Text Book of Operative Gynecology 10th edition. Lippincott Williams and Wilkins. 2011:727.

2. Farquar CM, Steiner CA. Hysterectomy rates in the united states 1990-1997.Obstet Gynaecol. 2002;99:229.

3. Hysterectomy. National Women's Health information center.2006-07-01, retrived. 2007-06-07.

4. Washington (state) protection and advocacy system The Asley treatment -Washington DC: National disabilities right New York. Retrieved. 2011;03:10.

5. Campbell ES, Xiao H, Smith MK. Types of hysterectomy: comparison of characteristics, hospital costs, utilization and outcomes. J Reprod Med. 2003;48(12):943-9.

6. Silva -Filho AL, Werneck RA, de magal haes RS, Belo AV, Triginelli. Abdominal Vs Vaginal hysterectomy: a comparative study of the post operative quality of life and satisfaction. Arch gynecol obstet. 2006;274:21-4.

7. Isthikhar R. Vaginal hysterectomy is superior than abdominal hysterectomy J.Surg pak. 2008;13:55-8.

8. Summit RL, Stovall TG, Steege JF, Lipscomb GH. A multicentre randomized comparison of laparoscopically assisted vaginal hysterectomy and abdominal hysterectomy. Obstet Gynaecol. 1998;92:321-6.

9. Ottosen C, Lingman G, Ottosen L. Three methods for hysterectomy a randomized prospective study of short term outcome British J Obstet Gyneco. 2000;107:1380-5.

10. Hwang JL, Seow KM, Jsai VL, Hwang LW, Hsiech $\mathrm{BC}$, Lee C. Comparative study of vaginal and abdominal hysterectomy for uterine myoma larger than $6 \mathrm{~cm}$ in diameter or uterus weighing at least 450g;a propective randomized study Acta Obstretrician ET Gynecol Scand. 2002;81:1132-8.

11. Garry R, fountain J, Mason S, Napp V, Brown J, Harve. The evaluate study: two parallel randomized trials, one comparing laparoscopic with abdominal hysterectomy, the other comparing laparoscopy with vaginal hysterectomy. British medical Journal. 2004;328(7432):129-33.

12. Aniulene R, Varzgaliene L, Varzgalis M. A comparative analysis of hysterectomies. Medicina (Kaunas). 2007;43(2):118-124.

13. Ribiero SC, Ribiero RM, Santos NC, pinotti JA. A randomized study of total abdominal, vaginal and laparoscopic hysterectomy. Int $\mathrm{J}$ Gynecol Obstet. 2003;83:37-43.

14. Meikle SF, Nugent EW, Orleans M. Complications recovery from LAVH compared with abdominal and vaginal hysterectomy. Obstet Gynecol. 1997;89:3.

15. Rosita A, Laima V, Manvydas VA. A comparative analysis of hysterectomies. Medicina (Kaunas) 2007;43(2):118-124.

16. Ferrari MM, Berlanda N, Mezzopane R, Ragusa G, Cavallo M, Pardi G. Identifying the indications for laparoscopically assisted vaginal hysterectomy: a prospective, randomised comparison with abdominal hysterectomy in patients with symptomatic uterine fibroids. British J Obstet Gynecol. 2000;107:620-5.

17. Schutz K, Possover M, Merker A, Michels A, Schneider A. Prospective randomized comparison of laparoscopic-assisted vaginal hysterectomy (LAVH) with abdominal hysterectomy $(\mathrm{AH})$ for the treatment of the uterus weighing >200g. Surg Endosc. 2002;16:121-5.

18. Muzii L, Basile S, Zupi E, Marconi D, Zullo MA, Manci $\mathrm{N}$, et al. Laparoscopic-assisted vaginal hysterectomy versus minilaparotomy hysterectomy: a prospective, randomized, multicenter study. J Minim Invasive Gynecol. 2007;14(5):610-5.

19. Kluivers KB, Johnson NP, Chien P, Vierhout ME, Bongers M, Mol BW. Comparison of laparoscopic and abdominal hysterectomy in terms of quality of life: a systematic review. Eur J Obstet Gynecol Reprod Biol. 2007;136(1):3-8.

20. Amirikia H, Evans TN. Ten-year review of hysterectomies: trends, indications, and risks. Am J Obstet Gynecol. 1979;134(4):431-7.

Cite this article as: Suraneni PD, Maharana S. Comparative study of abdominal, vaginal and laparoscopic assisted vaginal hysterectomies with special reference to immediate sequel, late sequel and complications. Int J Reprod Contracept Obstet Gynecol 2016;5:402-6. 